\title{
Stepwise Diagnosis for Rotating Machinery Using Force Identification Approach
}

\author{
Shozo Kawamura, Kazuhiro Niimi, Yuichi Kato, and Hirofumi Minamoto \\ Department of Mechanical Engineering, Toyohashi University of Technology, 1-1 Tempaku, Aichi, Toyohashi 441-8580, Japan \\ Correspondence should be addressed to Shozo Kawamura, kawamura@me.tut.ac.jp
}

Received 7 August 2011; Accepted 10 October 2011

Academic Editor: Joseph C. S. Lai

Copyright (๑) 2012 Shozo Kawamura et al. This is an open access article distributed under the Creative Commons Attribution License, which permits unrestricted use, distribution, and reproduction in any medium, provided the original work is properly cited.

\begin{abstract}
Machine condition monitoring and diagnosis have become increasingly important, and the application of these processes has been widely investigated. The authors previously proposed a stepwise diagnosis method for a beam structure. In that method, the location of the abnormality is first estimated using the force identification approach, and then the cause of the abnormality is identified. In this study, the stepwise diagnosis method was improved specifically for rotating machinery. The applicability of the proposed method was checked by using the experimental data. In the case of a rotor system with unbalance, it was shown that the location of the abnormality and its severity could be identified, and, in the case of a rotor system with stationary rubbing, the location of the abnormality could be accurately identified. Therefore, it was confirmed that the proposed diagnostic method is feasible for actual application.
\end{abstract}

\section{Introduction}

Machine condition monitoring and diagnosis have become increasingly important, and the application of these processes to beam structures and rotating machinery has been widely investigated. At the early stage of diagnosis, abnormality data is encountered, and a primary diagnosis is required to identify the location and cause of the abnormality.

There have been many studies about the primary diagnosis of abnormality. Some of them use a knowledge-based approach, that is, an expert system in which fault-symptom matrices, if-then rules, fuzzy logic, or neural networks are used. Others use a model-based approach in which the abnormal response is calculated from a mathematical model having a certain cause of abnormality, and the residual between the measured and simulated response is checked; the correct cause of abnormality can then be identified as the cause leading to the minimum residual. Many studies use a model-based approach to the crack diagnosis of a beam [1-5] and to the crack or unbalance diagnosis of a rotor system [6-10]. The authors previously proposed a stepwise primary diagnostic method [11] that was a modelbased approach in which the location of the abnormality is first estimated using the force identification approach. The distinguishing feature of the proposed method is that the abnormality is considered as an additional virtual external force in the early stage of abnormality. After that, the cause of the abnormality is identified. A numerical example showed that the location and cause of the abnormality could be identified with sufficient accuracy, and that this method was useful for primary diagnosis. Then the authors developed a new diagnostic approach to increase the robustness of the stepwise diagnosis method, where the mathematical model was modified based on the difference of the response between the measurement and the simulation [12]. The validity and applicability of the latter proposed method were shown for the experimental data of a free-free uniform beam excited at its center. The authors also proposed a new regularization method in the force identification procedure, and the method was proved to be feasible for actual application [13].

In this study, we propose a stepwise diagnostic approach specifically for rotating machinery. Stationary structures have been considered in previous work, with the recommendation that a vibration test be performed at regular intervals to monitor the health of the structure. In the case of rotating machinery, an unbalance force always exists within 
allowable limits; thus, no external force for the vibration test is necessary. The directions of the allowable unbalance force and the virtual external force due to abnormality are generally different; thus, we have to modify the treatment of the vibration change due to abnormality.

The applicability of the method was checked against experimental data. A rotor system of one disk or two disks with abnormal unbalance and a rotor system with rubbing were diagnosed. Of course, there are many causes of the abnormality in rotating machinery, such as unbalance, crack, rubbing, oil whip, oil whirl, and so on. Among them, we often encounter unbalance in the actual rotating machinery. The shaft vibrations and the accelerations at the bearing housings are measured in the normal and abnormal conditions, and then the location of the abnormality is estimated by using the force identification technique. After that, the cause of the abnormality and its severity are identified.

\section{Stepwise Fault Diagnosis Method}

2.1. Construction of the Mathematical Model. The stepwise diagnosis method [11] has been proposed for a beam structure. Here the method is modified for application to rotating machinery.

The rotating machinery is modelled without damping. In fact, when an abnormality occurs in machinery, its mechanical properties such as mass and stiffness can change, which in turn alters the natural frequency; however, in the proposed method, the abnormality is considered an additional external force for normal machinery, so the natural frequency does not vary. Thus, response data near the critical speed cannot be used for this diagnosis approach, and response data far from the critical speed is almost the same in the cases with and without damping for machinery with light damping. Actually, rotating machinery does not operate near the critical speed. Therefore, for simplicity of treatment, machinery without damping is considered in this study. And the nonlinear effect and the gyroscopic effect are also ignored because the machinery considered in this study is very simple.

The mass matrix $[M]$ and the stiffness matrix $[K]$ under normal conditions were constructed in advance using the Finite Element Method (FEM), and they are modified by the model update procedure so that the simulated response sufficiently agrees with the experimental one.

In the case of rotating machinery, an allowable unbalance force usually exists, and it can be used as the external force of vibration test. Its magnitude is given as $M_{\text {disc }} \varepsilon \omega^{2}$, where $M_{\text {disc }}$ is the mass of the disk, $\varepsilon$ is the eccentricity, and $\omega$ is the rotational speed, respectively. The unbalance force in the horizontal direction is $M_{\text {disc }} \varepsilon \omega^{2} \cos \omega t$ while that in the vertical direction is $M_{\text {disc }} \varepsilon \omega^{2} \sin \omega t$. In the case of stationary structures, the virtual external force due to the abnormality acts on the structure in the same direction as the external force of the vibration test. But for the rotating machinery, the direction of the external force due to the abnormality is not same as that of the allowable unbalance force. The unbalance, for example, may occur at an arbitrary position of the disk.
Thus, in this study, only the external force and the response in one direction are considered. The equation of motion and the output equation under normal conditions are obtained as follows:

$$
[M]\left\{\ddot{x}_{n}\right\}+[K]\left\{x_{n}\right\}=\{f\}, \quad\left\{x_{m}\right\}=[C]\left\{x_{n}\right\},
$$

where $\left\{x_{n}\right\}$ is the vertical response of the rotating machinery which consists of the translational and rotational displacements, and $\{f\}$ is the allowable translational unbalance force expressed as follows in the case of the rotor system of one disk:

$$
\{f\}=\left\{\begin{array}{lllllll}
0 & \cdots & 0 & M_{\text {disc }} \mathcal{E} \omega^{2} & 0 & \cdots & 0
\end{array}\right\}^{T} \sin \omega t .
$$

The centrifugal force $M_{\text {disc }} \varepsilon \omega^{2}$ is located at the element corresponding to the disk position. And $[C]$ is the coefficient matrix which expresses the measurement positions and directions, that is, the translational displacements only are measured.

2.2. Estimation of the Location of the Abnormality. In the abnormal conditions, the response changes because the mass and/or stiffness matrices change due to abnormality, even if the same allowable unbalance force acts on the machinery. However, the change of response is considered to be the result of an additional external force, $\left\{f_{a}\right\}$, exerted on the normal machinery as follows:

$$
[M]\left\{\ddot{x}_{a}\right\}+[K]\left\{x_{a}\right\}=\{f\}+\left\{f_{a}\right\},
$$

where

$$
\left\{x_{a}\right\}=\left\{x_{n}\right\}+\{\Delta x\}, \quad\left\{\Delta x_{m}\right\}=[C]\{\Delta x\} .
$$

The external force $\left\{f_{a}\right\}$ is expressed as

$$
\left\{f_{a}\right\}=\left\{\begin{array}{llllllll}
0 & \cdots & 0 & F_{a} & 0 & \cdots & 0
\end{array}\right\}^{T} \sin (\omega t+\phi),
$$

where $F_{a}$ is set at the location of the abnormality, and the angle $\phi$ is the direction of the abnormality from the direction of the allowable unbalance force. An abnormality in the early stage occurs locally in the machinery, so that the additional external force is considered to act only on the $i$ th element of the finite element model. The difference $\{\Delta x\}$ of the response is synchronous with the additional external force due to the abnormality. The component of $\omega$ from the difference $\{\Delta x\}$ is extracted by the frequency analysis procedure, and the magnitudes of $\{\Delta x\}$ and $\left\{f_{a}\right\}$ are defined as $\{\Delta X\}$ and $\left\{F_{a}\right\}$, respectively. Their relationship is expressed as follows:

$$
\left([K]-\omega^{2}[M]\right)\{\Delta X\}=\left\{F_{a}\right\} .
$$

The magnitude of the measured response $\left\{\Delta X_{m}\right\}$ is defined as $[C]\{\Delta X\}$, and the additional external force $\left\{F_{a i}\right\}$ of the $i$ th element can be identified using the relationship

$$
\left\{\Delta X_{m}\right\}=[H(\omega)]\left\{F_{a i}\right\},
$$

where $[H(\omega)]$ is a compliance matrix between the measured responses and the assumed external force. In the actual 


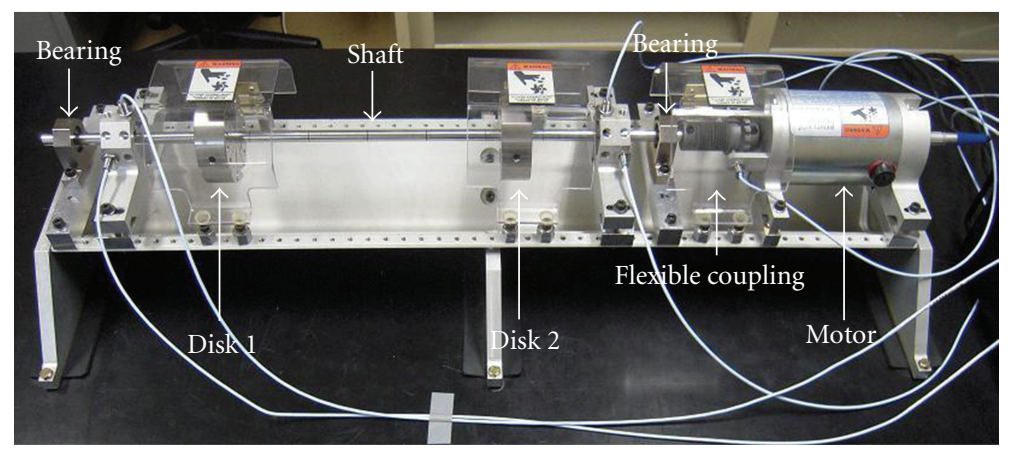

Figure 1: Experimental setup.

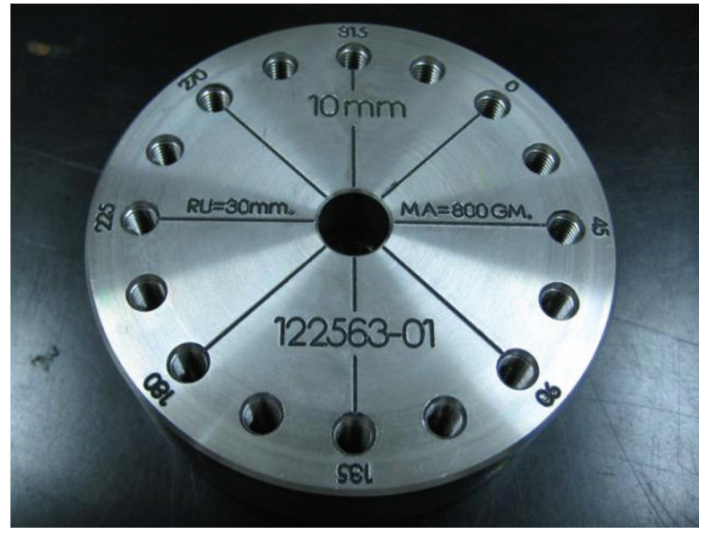

Figure 2: Experimental disk.

practice of solving (7), the compliance matrix $[H(\omega)]$ is often ill-posed, and thus the truncation of small singular values is needed. Then, $\left\{F_{a i}\right\}$ is identified and $\left\{\Delta X_{m i}\right\}$ can be obtained.

The next objective function, $J_{1}$, is calculated for every element number, $i$, as follows:

$$
J_{1}=\left|\left\{\Delta X_{m}\right\}-\left\{\Delta X_{m i}\right\}\right|
$$

where $|\bullet|$ represents the Euclidean norm. It is considered that the abnormality will occur at the element where $J_{1}$ is significantly small.

2.3. Identification of the Cause of the Abnormality. After the location of the abnormality is thus estimated as the $I$ th element, we consider the possible causes of the abnormality. One cause is set as $(j)$. A mathematical model with the cause of abnormality $(j)$ in the $I$ th element is constructed. The mass and stiffness matrices are expressed as $\left[M_{a I}^{(j)}\right]$ and $\left[K_{a I}^{(j)}\right]$, respectively. The subscript " $a$ " means that the matrix has an abnormality. The response $\left\{X_{a I}^{(j)}\right\}$ is calculated under the normal unbalance force using the equation of motion,

$$
\left(\left[K_{a I}^{(j)}\right]-\omega^{2}\left[M_{a I}^{(j)}\right]\right)\left\{X_{a I}^{(j)}\right\}=\{F\},
$$

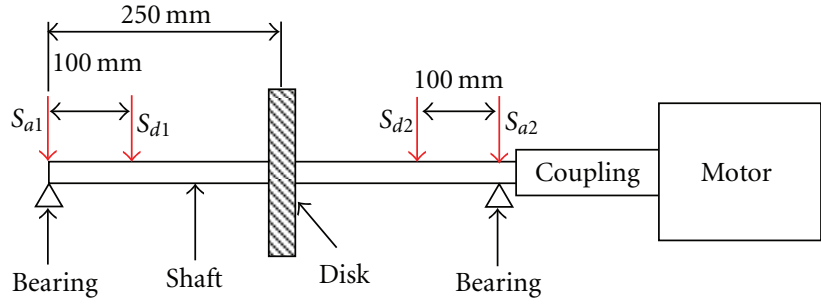

(a) A rotor system of one disk

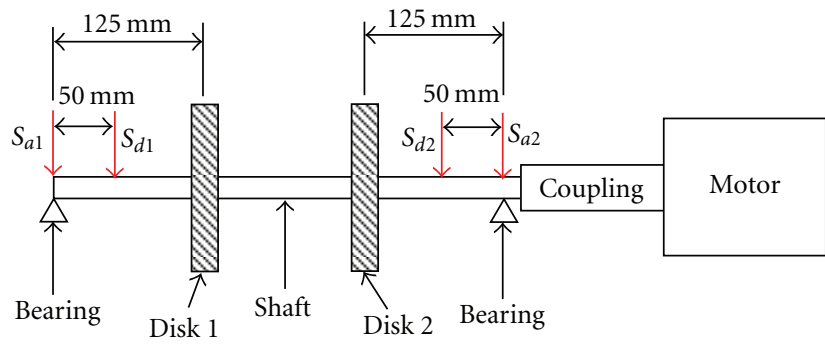

(b) A rotor system of two disks

Figure 3: Sensor and disk locations.

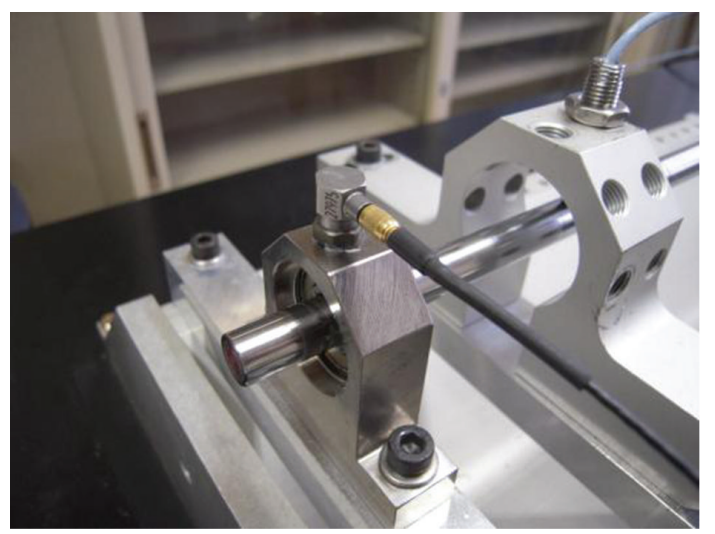

Figure 4: A displacement sensor and an accelerometer on the bearing housing.

and the vibration difference at the measurement points is obtained as follows:

$$
\left\{\Delta X_{a I m}^{(j)}\right\}=[C]\left(\left\{X_{a I}^{(j)}\right\}-\left\{X_{m s}\right\}\right),
$$

where $\left\{X_{m s}\right\}$ is the normal response. 


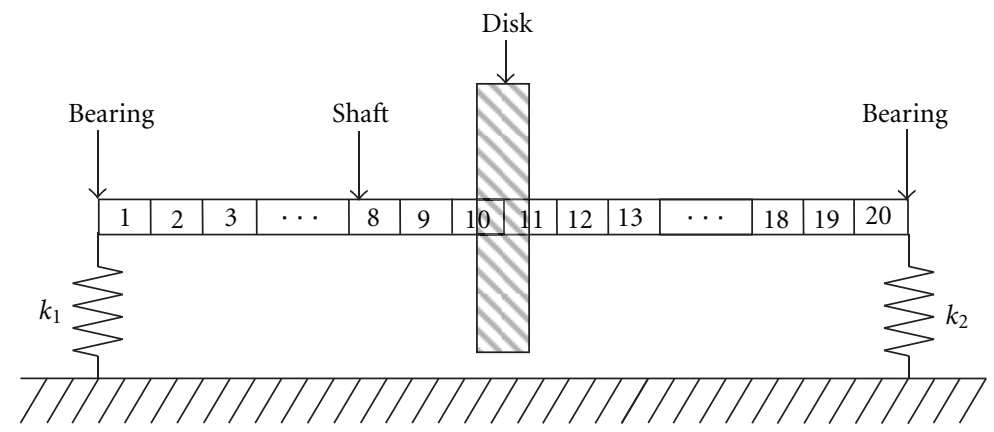

(a) A rotor system of one disk

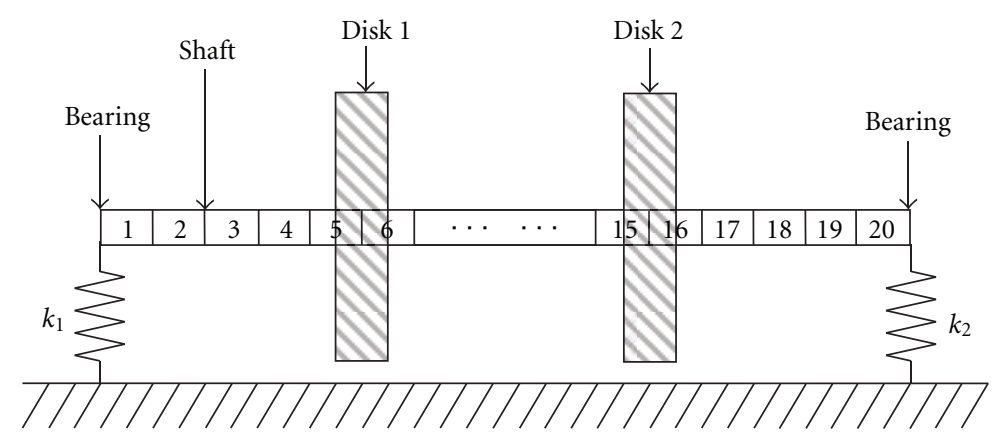

(b) A rotor system of two disks

Figure 5: Finite element model of rotor system.

The next objective function, $J_{2}$, is calculated as

$$
J_{2}=\left|\left\{\Delta X_{m}\right\}-\left\{\Delta X_{a I m}^{(j)}\right\}\right|,
$$

and the cause of the abnormality is identified when $J_{2}$ is significantly small. follows,

The procedure of the diagnosis method is summarized as

(1) Monitoring of the shaft vibration, Detection of an abnormality when the shaft vibration exceeds the threshold value.

(2) Calculation of the vibration change and estimation of the location of the abnormality, and

(3) Identification of the cause of the abnormality.

\section{Experimental Setup and Analytical Model}

The diagnosis method previously proposed [11] was confirmed its validity for the beam structure. In this study, the method is improved for the rotating machinery though the fundamental idea is common. Therefore, in this study, we will skip the numerical example to check the validity of the method and check the applicability of the proposed method using experimental data. In this section, the experimental setup and its analytical model are shown.

3.1. Experimental Setup. Figure 1 shows the experiment setup in the case of two disks, which is a model rotor system made by Bently Nevada (General Electric). This rotor system can simulate various abnormalities such as unbalance, rubbing, and so on. In this study, a shaft with one disk or two disks supported by rolling bearings was considered. The length and the diameter of the shaft were $0.5 \mathrm{~m}$ and $0.01 \mathrm{~m}$, respectively. In the case of one disk, the disk was set at the center of the shaft while, in the case of two disks, they were set $0.125 \mathrm{~m}$ from the bearing locations. Figure 2 shows an $800 \mathrm{~g}$ disk with holes at intervals of 22.5 degrees and $0.03 \mathrm{~m}$ in the radius from the disk center. A certain weight can be added for balancing or simulating an unbalance condition.

To measure the vertical responses of the rotor system, two displacement sensors and two accelerometers were used. The sensor locations are shown in Figure 3. An accelerometer is attached on the bearing housing, and a displacement sensor is set as shown in Figure 4.

3.2. Analytical Model. Figure 5 shows the analytical models of one disk and two disks, namely, a shaft with one disk or two disks elastically supported at both ends. To construct a mathematical model, the shaft was divided into 20 elements, and the characteristic matrices were obtained by FEM using a beam element.

\section{Diagnosis of a Rotor System of One Disk with Unbalance}

4.1. Response under Normal Conditions and Its Mathematical Model. The rotor system of one disk as shown in Figure 5(a) was considered first. In the initial condition, it was shown 


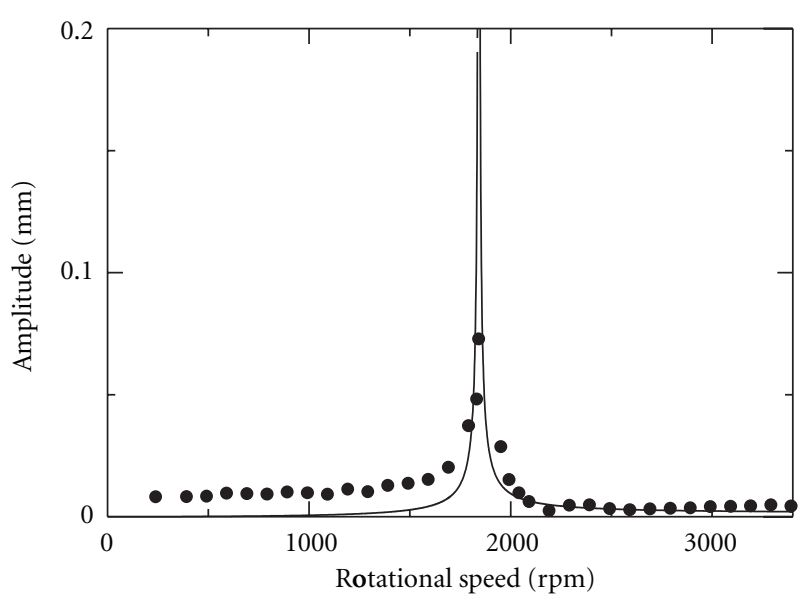

- Experimental data

- Simulation data

(a) Sensor $S_{d 1}$

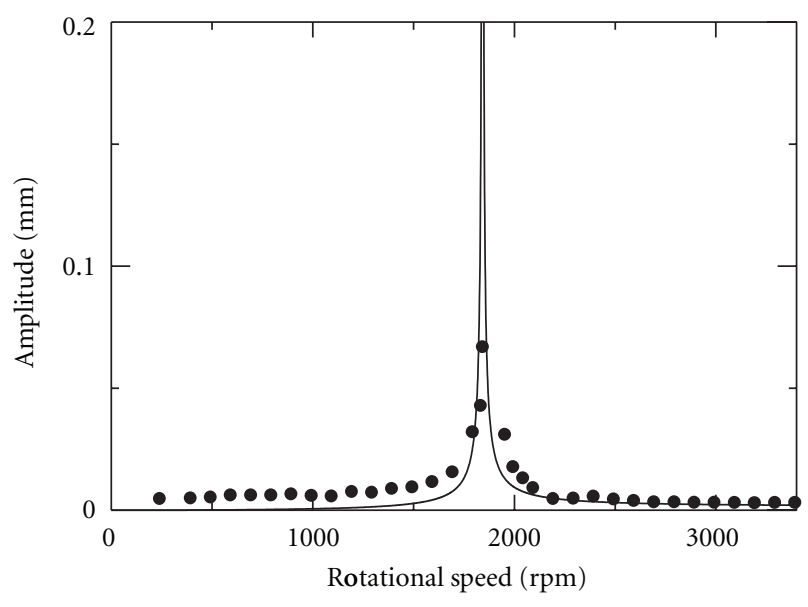

- Experimental data

- Simulation data

(b) Sensor $S_{d 2}$

FIgURE 6: Amplitude of shaft vibration under normal conditions.

that the shaft vibration was large because of the initial unbalance, and the critical speed was about $1860 \mathrm{rpm}$. Thus, the operating speed was set as $2700 \mathrm{rpm}$, and the balancing was carried out using trial weight to suppress the shaft vibration at the operating speed. The amplitude of the shaft vibration is shown in Figure 6.

Then the mathematical model under normal conditions was constructed by identifying the spring constants of the bearings and the residual amount of unbalance. The identified results were as follows:

$$
\begin{gathered}
k_{1}=1.83 \times 10^{5}[\mathrm{~N} / \mathrm{m}], k_{2}=2.02 \times 10^{5}[\mathrm{~N} / \mathrm{m}], \\
U_{\text {res }}=M_{\text {rotor }} \varepsilon=800[\mathrm{~g}] \times 2.8 \times 10^{-3}[\mathrm{~mm}]=2.24[\mathrm{~g} \cdot \mathrm{mm}] .
\end{gathered}
$$

In Figure 6, the simulated amplitude of the shaft vibration is also shown.

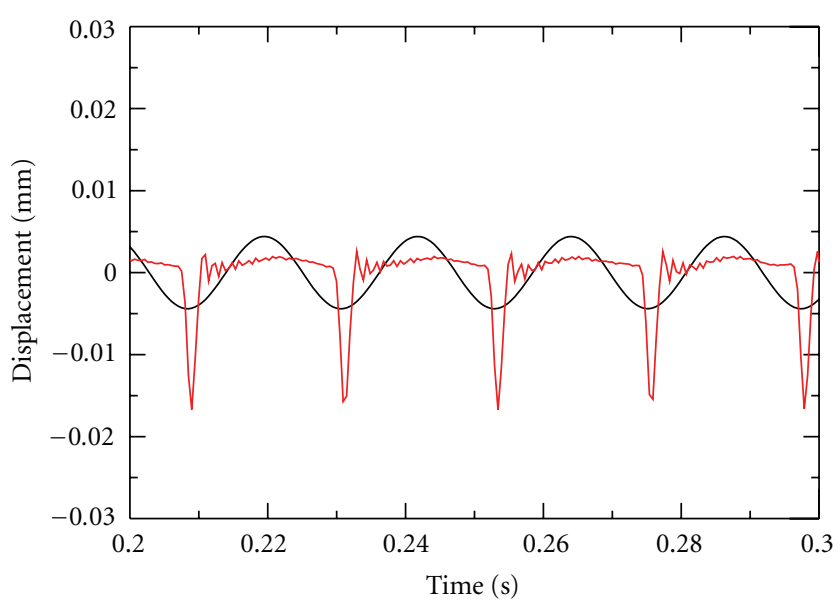

(a) In the case of the normal condition

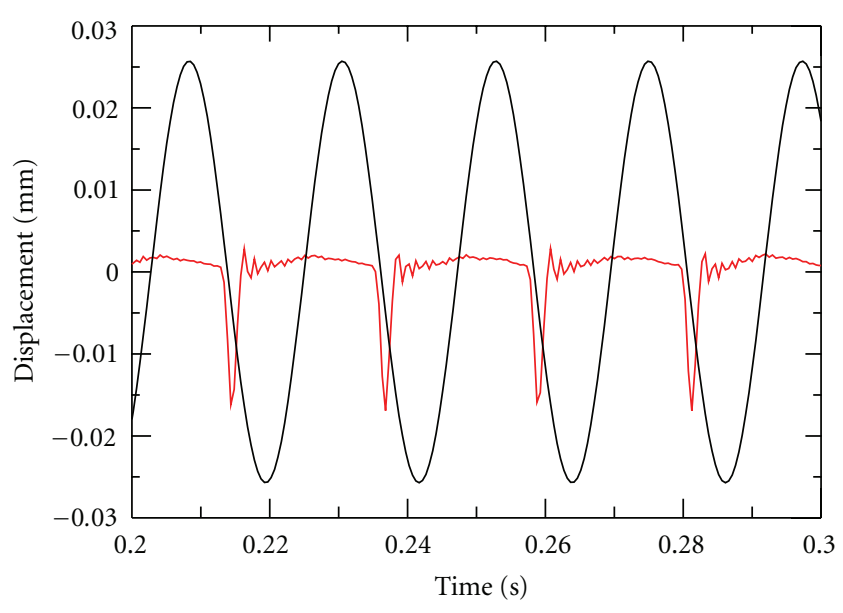

(b) In the case of the abnormal condition

FIGURE 7: Time history of shaft vibration and pulse signal at sensor $S_{d 1}$.

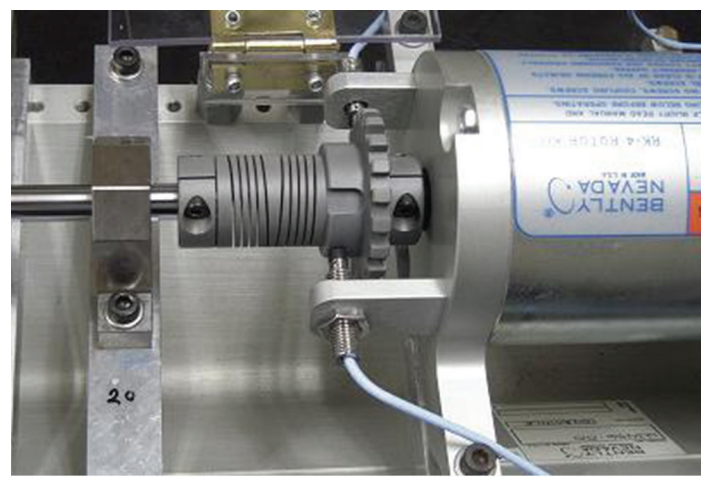

FIgURE 8: The keyway.

4.2. Response under Abnormal Conditions and Definition of Vibration Difference. The time histories of the vertical shaft vibration under normal and abnormal conditions are shown in Figure 7. These results are the frequency component of $2700 \mathrm{rpm}$ extracted from the measured data. As shown in Figure 8, the pulse signal of the keyway attached near the 


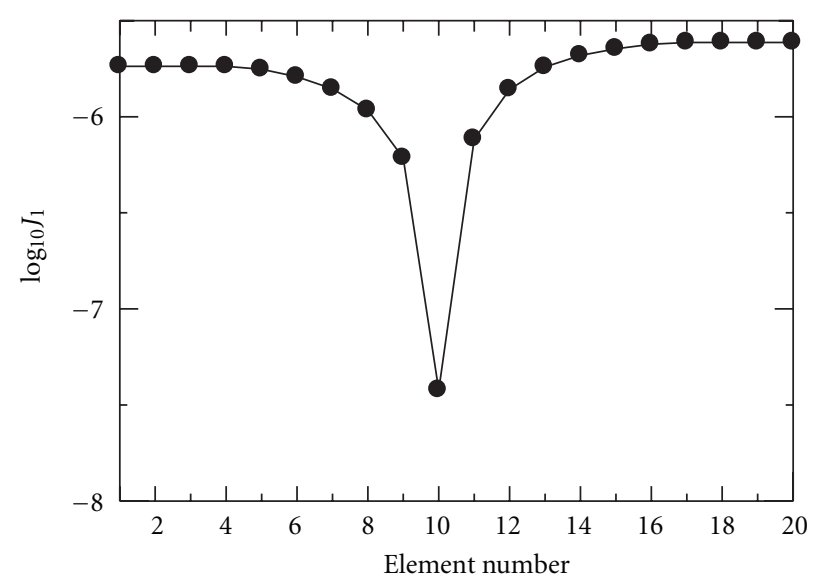

(a)

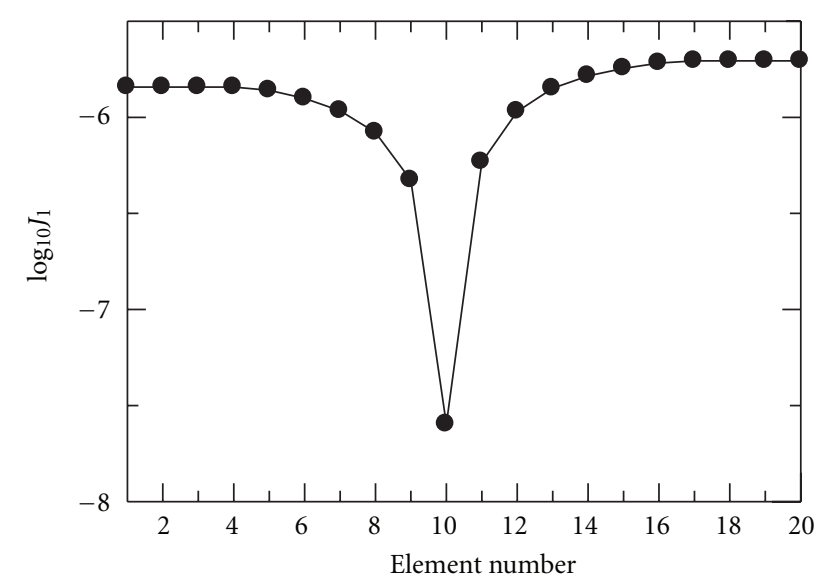

(c)

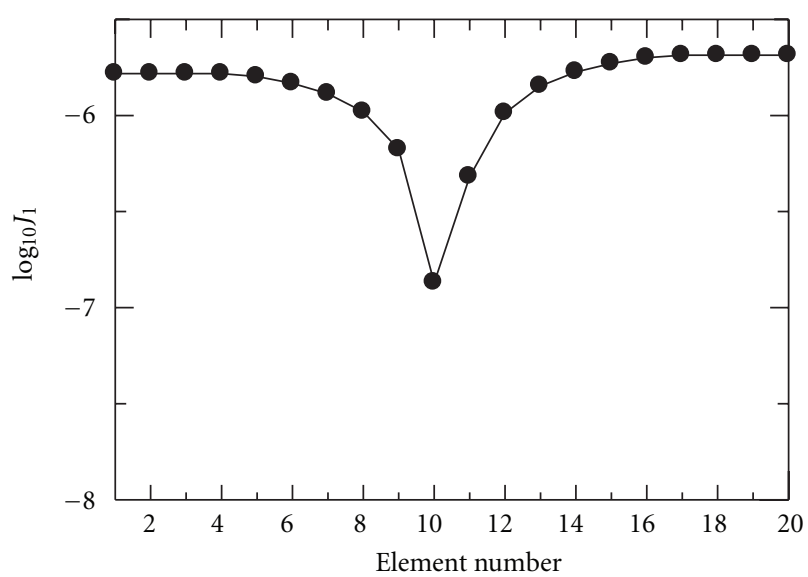

(b)

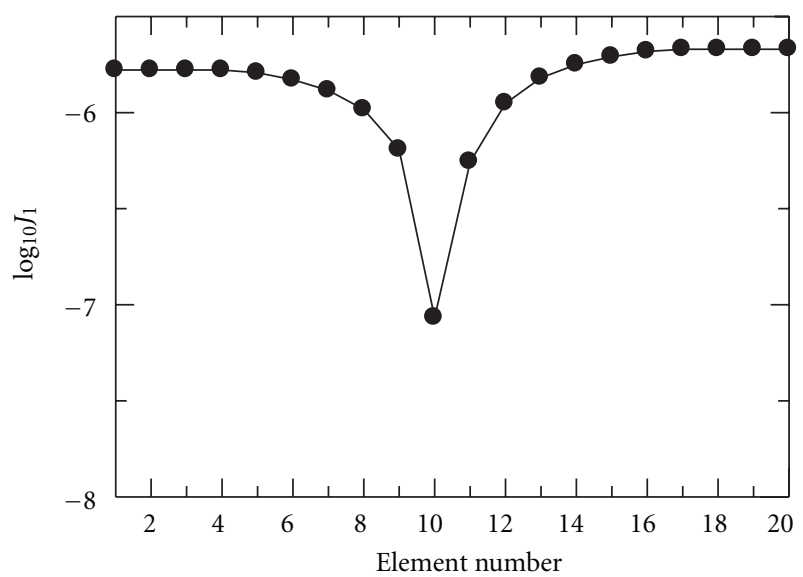

(d)

FIGURE 9: Objective function in the case of rotor of one disk. (a) In the case that an unbalance is at 0 degree from the keyway. (b) In the case that an unbalance is at 90 degrees from the keyway. (c) In the case that an unbalance is at 180 degrees from the keyway. (d) In the case that an unbalance is at 270 degrees from the keyway.

coupling is measured by a displacement sensor set in the horizontal direction, while the shaft vibration is measured in the vertical direction. Thus, the vibration signal in Figure 7 has been shifted 90 degrees from the original data. Under normal conditions, when the pulse signal appears, that is, the keyway is at the sensor location as shown in Figure 7(a), the shaft was close to the sensor. The rotational speed, $2700 \mathrm{rpm}$, is over the critical speed; thus, the residual unbalance was located at the opposite side of the keyway.

An example under abnormal conditions is shown in Figure $7(\mathrm{~b})$ when the unbalance weight $0.4 \mathrm{~g}$ (amount of unbalance $0.4[\mathrm{~g}] \times 30.0[\mathrm{~mm}]=12.0[\mathrm{~g} \cdot \mathrm{mm}])$ was attached at 90 degrees from the keyway. The shaft vibration was larger than in the normal case, and the shaft was closest to the sensor at a 90 degrees shift from the pulse signal because of the unbalance. This shaft vibration is $\left\{x_{a}\right\}$ in (4).

The vibration difference $\{\Delta x\}$ was obtained by subtracting the normal data from the abnormality data with the two signals aligned with respect to the pulse signal and calculating the amplitude of the response.
4.3. Estimation of the Location of the Abnormality. To obtain the objective function $J_{1}$, the inverse problem in (7) is solved. In this study, we use the beam element to express the rotor system so that the external force vector $\left\{F_{a i}\right\}$ has four elements as follows:

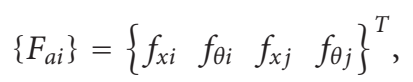

where $f_{x i}$ and $f_{x j}$ are the translational forces at both ends of the $i$ th element, respectively, and $f_{\theta i}$ and $f_{\theta j}$ are the bending moments at both ends of the $i$ th element, respectively. The displacements are measured at four points so that the compliance matrix has four singular values. Although there are only four singular values, some of them are very small with respect to the spatial relationship between the sensor and the additional external force. If a small singular value is adopted in the identification process, the identified external force becomes very large so that it cannot be considered as an additional external force corresponding to an abnormality in the early stage. In this study, the external forces are identified for various truncation orders of singular values, 


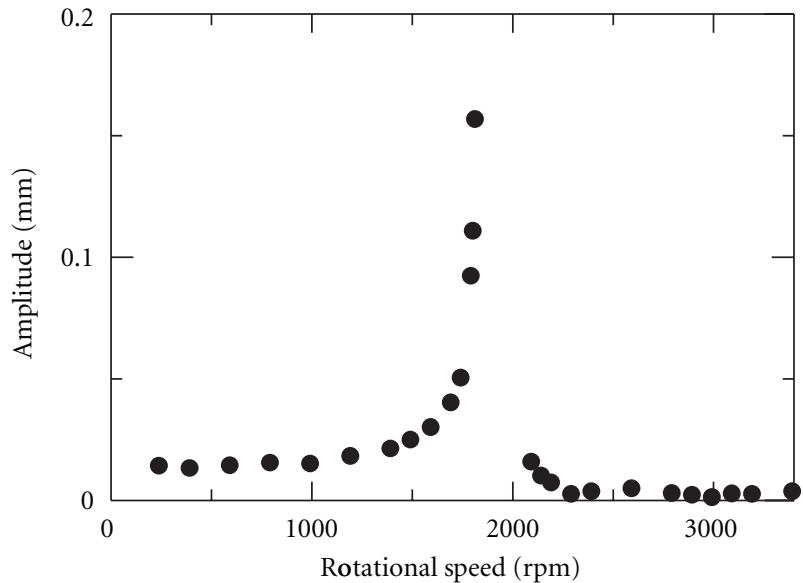

(a) Sensor $S_{d 1}$

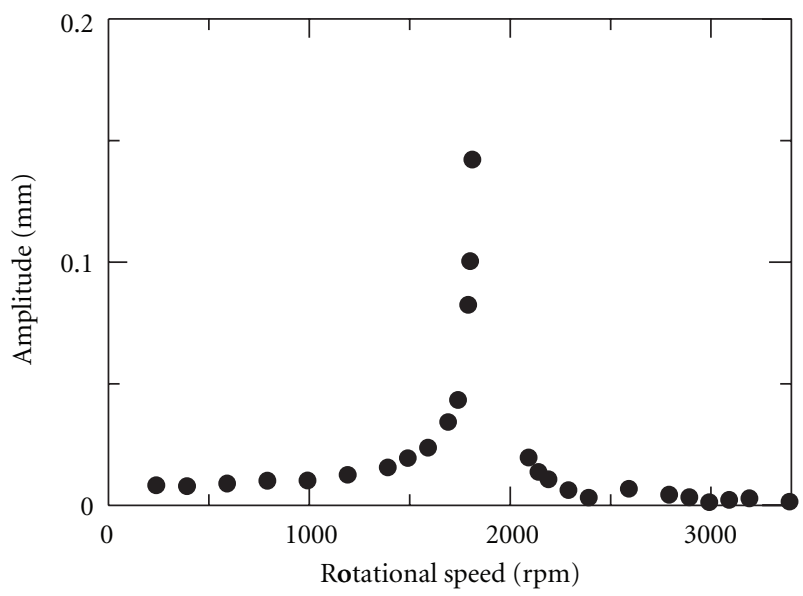

(b) Sensor $S_{d 2}$

Figure 10: Amplitude of shaft vibration under abnormal conditions.

and the magnitudes of the forces are checked. Then, we adopt a singular value.

Some results of estimation for various angles of unbalance are shown in Figure 9. The horizontal axis is the element number where the virtual external force is assumed, and the vertical axis is the objective function of (8). The location of the minimum objective function is considered as the site of the abnormality.

In this experiment, the disk is set at the center of the shaft so that the element number of the disk is 10 or 11 . From the figures, the objective functions show the minimum value at number 10 or 11 . Therefore, it is shown that the location of the abnormality can be estimated for various angles of unbalance on the disk.

4.4. Estimation of the Cause of the Abnormality and Its Severity. After estimation of the location of the abnormality, the cause of the abnormality and its severity are estimated. In this experiment, the location of the abnormality was estimated at the disk position, so that the unbalance is assumed as a cause of abnormality because the synchronous
TABLE 1: The severity of unbalance.

\begin{tabular}{|c|c|c|c|}
\hline & Exact value & Identified value & Error \\
\hline \multirow{2}{*}{$\begin{array}{c}\text { Case } 1 \text { unbalance }[\mathrm{g} \cdot \mathrm{mm} \text { ] } \\
\text { angle [deg.] }\end{array}$} & 12.0 & 12.9 & 0.9 \\
\hline & 0 & -9.9 & -9.9 \\
\hline \multirow{2}{*}{$\begin{array}{c}\text { Case } 2 \begin{array}{c}\text { unbalance }[\mathrm{g} \cdot \mathrm{mm} \text { ] } \\
\text { angle [deg.] }\end{array} \\
\end{array}$} & 12.0 & 13.2 & 1.2 \\
\hline & 45 & 45.4 & 0.4 \\
\hline \multirow{2}{*}{$\begin{array}{c}\text { Case } 3 \begin{array}{c}\text { unbalance }[\mathrm{g} \cdot \mathrm{mm} \text { ] } \\
\text { angle [deg.] }\end{array} \\
\end{array}$} & 12.0 & 13.2 & 1.2 \\
\hline & 90 & 88.9 & -1.1 \\
\hline \multirow{2}{*}{ Case $4 \begin{array}{c}\text { unbalance }[\mathrm{g} \cdot \mathrm{mm} \text { ] } \\
\text { angle [deg.] }\end{array}$} & 12.0 & 13.2 & 1.2 \\
\hline & 135 & 136.4 & 1.4 \\
\hline \multirow{2}{*}{$\begin{array}{c}\text { Case } 5 \begin{array}{c}\text { unbalance }[\mathrm{g} \cdot \mathrm{mm}] \\
\text { angle [deg.] }\end{array} \\
\end{array}$} & 12.0 & 13.2 & 1.2 \\
\hline & 180 & 179.9 & -0.1 \\
\hline \multirow{2}{*}{$\begin{array}{c}\text { Case } 6 \begin{array}{c}\text { unbalance }[\mathrm{g} \cdot \mathrm{mm} \text { ] } \\
\text { angle [deg.] }\end{array} \\
\end{array}$} & 12.0 & 12.9 & 0.9 \\
\hline & 225 & 227.4 & 2.4 \\
\hline \multirow{2}{*}{$\begin{array}{c}\text { Case } 7 \begin{array}{c}\text { unbalance }[\mathrm{g} \cdot \mathrm{mm} \text { ] } \\
\text { angle [deg.] }\end{array} \\
\end{array}$} & 12.0 & 12.6 & 0.6 \\
\hline & 270 & 270.9 & 0.9 \\
\hline \multirow{2}{*}{ Case $8 \begin{array}{c}\text { unbalance }[\mathrm{g} \cdot \mathrm{mm} \text { ] } \\
\text { angle [deg.] }\end{array}$} & 12.0 & 12.6 & 0.6 \\
\hline & 315 & 310.4 & -4.6 \\
\hline
\end{tabular}

frequency with the rotating speed changes, which is usually reflective of unbalance. Here the amount and angle of unbalance have to be identified. The angle of unbalance is defined from the keyway. The objective function $J_{2}$ is calculated for various amounts and angles of unbalance on the disk, and the results are shown in Table 1. The error means the difference between the exact value and the identified value. From this table, it is shown that excellent identification results can be obtained.

\section{Diagnosis of a Rotor System of Two Disks with Unbalance}

5.1. Response under Normal Conditions and Its Mathematical Model. Next, a rotor system of two disks as shown in Figure 5(b) was considered. To simulate normal conditions, the balancing was carried out using the influence coefficient method. The shaft vibration under normal conditions is shown in Figure 10. The critical speed was about $1875 \mathrm{rpm}$; thus, in this study, the operating speed was set as $3000 \mathrm{rpm}$.

The mathematical model was then constructed. To present the experimental shaft vibration by the mathematical model, the parameters of the spring constants at both ends, the amounts of unbalance of the two disks, and the relative angle of residual unbalance were identified. In this experiment, the shaft vibration around the operating speed was very small, so two types of mathematical models were considered. The one represents the experimental shaft vibration at $3000 \mathrm{rpm}$, and the other represents the vibrations from $2800 \mathrm{rpm}$ to $3200 \mathrm{rpm}$ on average. Sufficient estimations of the location of the abnormality could not be obtained using the latter mathematical model. The result shows that the mathematical model at the exact operating speed is required to obtain good results. In this experiment, the shaft vibration under normal conditions was very small after balancing, so that the construction of a mathematical 


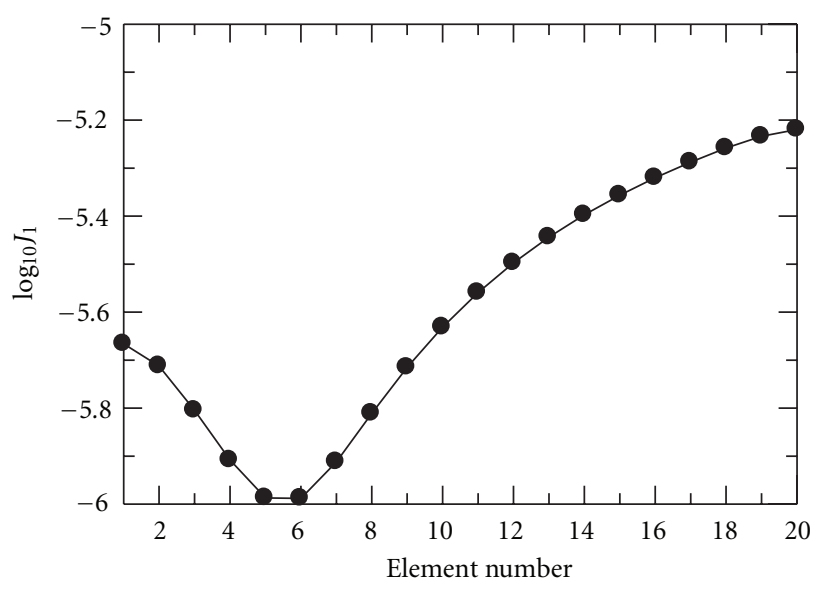

(a)

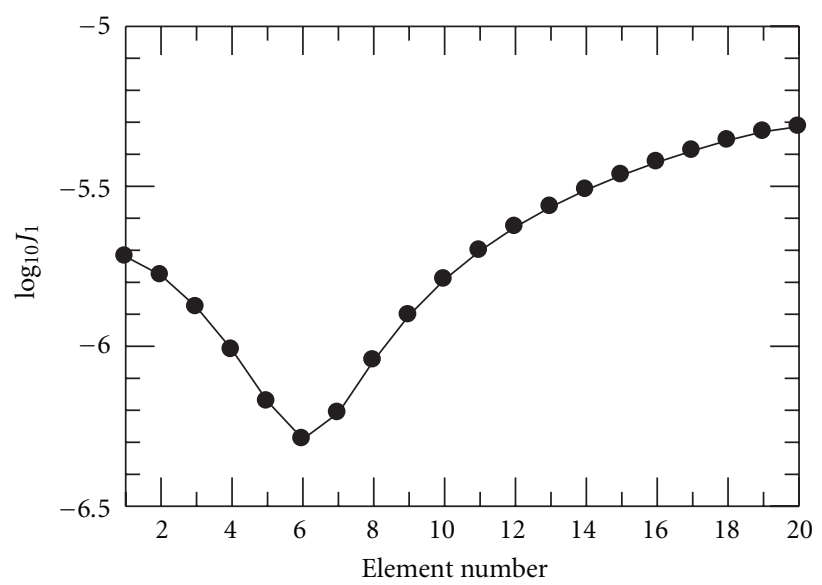

(c)

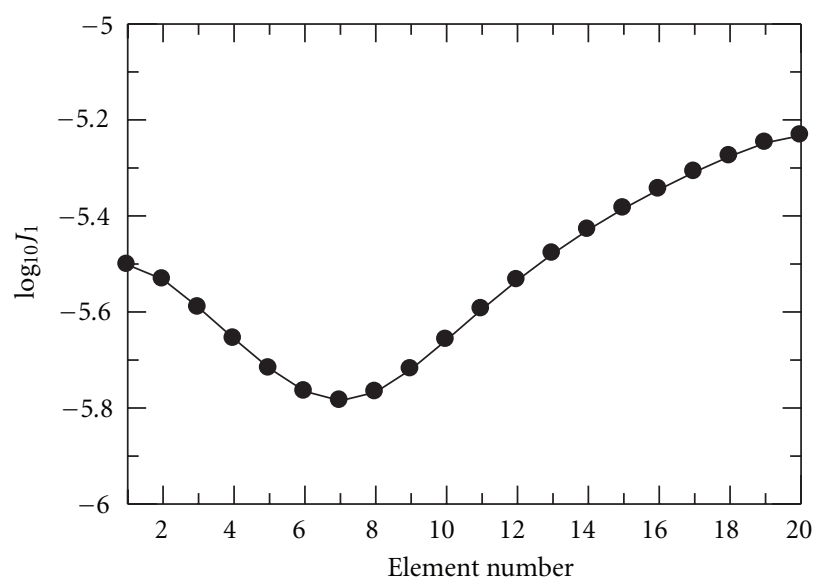

(b)

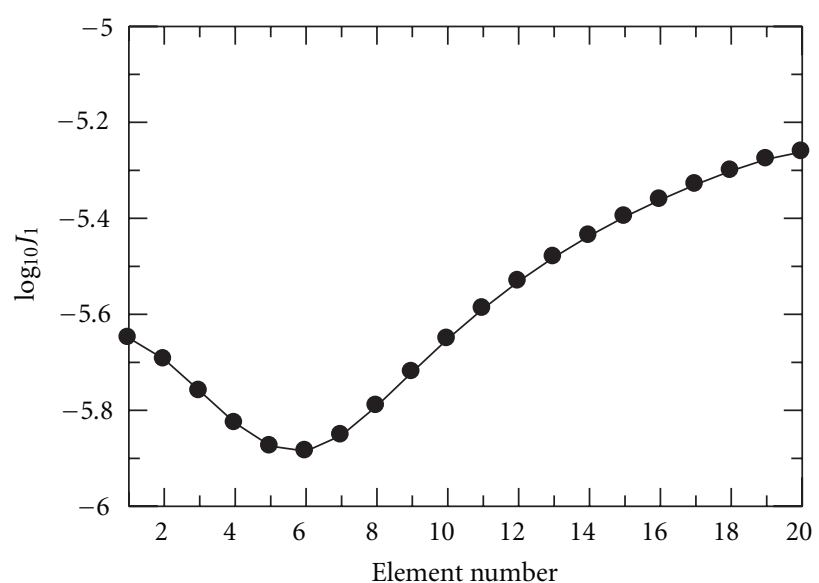

(d)

FIgURE 11: Objective function $J_{1}$ in the case of Disk 1 with unbalance. (a) In the case that an unbalance is at 0 degree from the keyway. (b) In the case that an unbalance is at 90 degrees from the keyway. (c) In the case that an unbalance is at 180 degrees from the keyway. (d) In the case that an unbalance is at 270 degrees from the keyway.

model proved difficult. In the case of the stationary structures in our previous studies $[6,7]$, the vibration under normal conditions by a vibration test was not so small. We are considering this point as a future problem. In this study, the mathematical model representing the experimental shaft vibration at $3000 \mathrm{rpm}$ was adopted, and the parameters were as follows:

$$
\begin{aligned}
k_{1}=1.00 & \times 10^{7}[\mathrm{~N} / \mathrm{m}], \quad k_{2}=1.00 \times 10^{7}[\mathrm{~N} / \mathrm{m}], \\
U_{\text {res } 1} & =M_{\text {rotor }} \varepsilon_{1}=800[\mathrm{~g}] \times 6.2 \times 10^{-3}[\mathrm{~mm}] \\
& =4.96[\mathrm{~g} \cdot \mathrm{mm}], \\
U_{\text {res2 }} & =M_{\text {rotor }} \varepsilon_{2}=800[\mathrm{~g}] \times 6.0 \times 10^{-3}[\mathrm{~mm}] \\
& =4.80[\mathrm{~g} \cdot \mathrm{mm}], \quad \theta=213.4[\text { deg. }] .
\end{aligned}
$$

5.2. Estimation of the Location of the Abnormality. Figure 11 shows some estimation results of the case of Disk 1 with unbalance. Disk 1 is located at element number 5 or 6 .
From the figure, good estimation results can be obtained for various angles of unbalance. Figure 12 shows some results of the case of Disk 2 with unbalance. Disk 2 is located at element number 15 or 16. From the figure, good estimation results can be obtained for various angles of unbalance.

5.3. Estimation of the Cause of the Abnormality and Its Severity. In this case, the location of the abnormality was also estimated at the disk position; thus, the unbalance was assumed as a cause of abnormality. The estimation results of the amount and angle of unbalance are shown in Tables 2 and 3. From these tables, it is shown that the identification results are slightly less accurate than in the case of a single disk; that is, the largest error of the angle is 26.0 degrees. In this experiment, it is shown that the angle can be estimated within an error of 30 degrees. Accurate result may be obtained using more accurate mathematical model, but the construction of the accurate mathematical model is difficult because the shaft vibration is very small after balancing as mentioned in Section 5.1. 


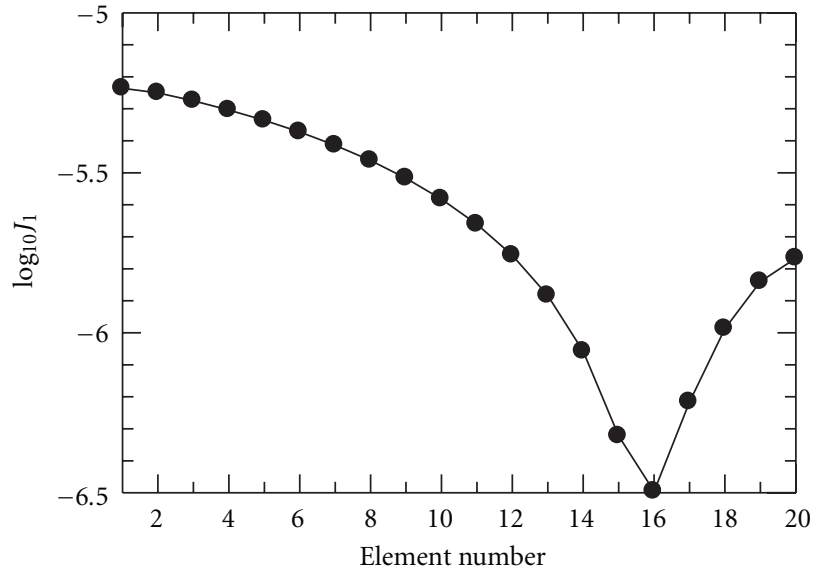

(a)

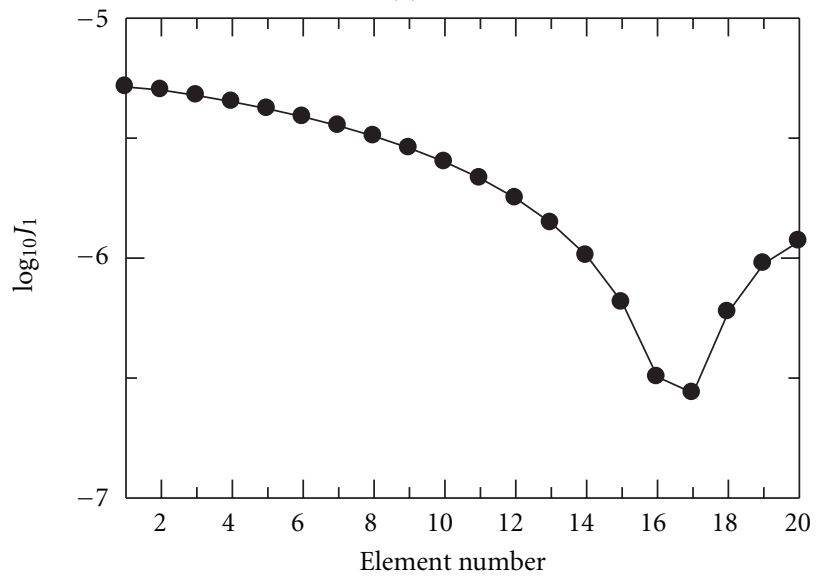

(c)

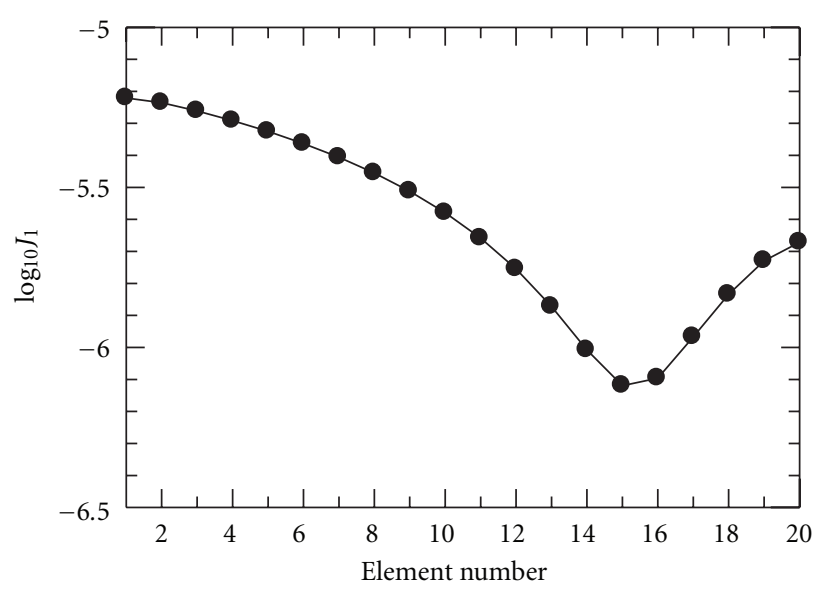

(b)

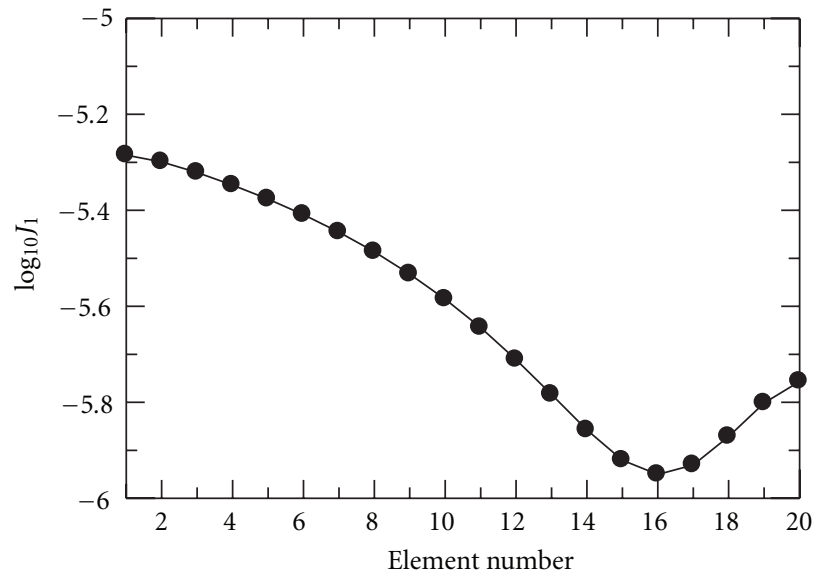

(d)

FIgURE 12: Objective function $J_{1}$ in the case of Disk 2 with unbalance. (a) In the case that an unbalance is at 0 degree from the keyway. (b) In the case that an unbalance is at 90 degrees from the keyway. (c) In the case that an unbalance is at 180 degrees from the keyway. (d) In the case that an unbalance is at 270 degrees from the keyway.

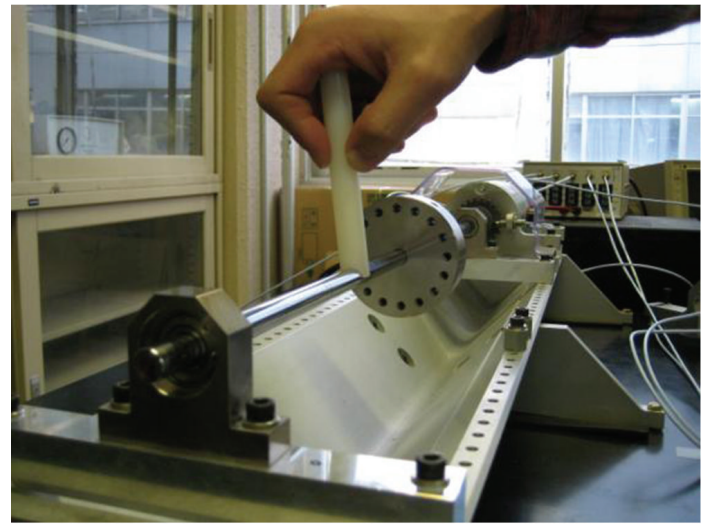

Figure 13: Experiment for stationary rubbing.

\section{Diagnosis of a Rotor System of One Disk with Stationary Rubbing}

In this section, the stationary rubbing of the shaft is considered an abnormality. The normal rotor system was constructed by balancing and the mathematical model was obtained by identifying the parameters as follows:

$$
\begin{gathered}
k_{1}=1.60 \times 10^{5}[\mathrm{~N} / \mathrm{m}], \quad k_{2}=1.81 \times 10^{5}[\mathrm{~N} / \mathrm{m}], \\
U_{\text {res }}=M_{\text {rotor }} \varepsilon=800[\mathrm{~g}] \times 2.6 \times 10^{-3}[\mathrm{~mm}]=2.08[\mathrm{~g} \cdot \mathrm{mm}] .
\end{gathered}
$$

Stationary rubbing was induced by pressing a bar on the shaft as shown in Figure 13. The pressing force was about $75 \mathrm{~N}$ measured by a push-pull gage (IMADA DPS-50R). The locations of rubbing were set at $50 \mathrm{~mm}, 150 \mathrm{~mm}, 200 \mathrm{~mm}$, $300 \mathrm{~mm}, 350 \mathrm{~mm}$, and $400 \mathrm{~mm}$ from the left bearing. These locations correspond to the element number 2 or 3,6 or 7,8 or 9,12 or 13,14 or 15 , and 18 or 19 , respectively.

Some estimation results for the location of the abnormality are shown in Figure 14. From these results, various rubbing locations could be accurately estimated.

In this case, the estimation of abnormality type is not performed because the location of the abnormality is considered to be of prime importance in the actual application. In the actual rotating machinery, we can first check the rotor system at the estimated location. 


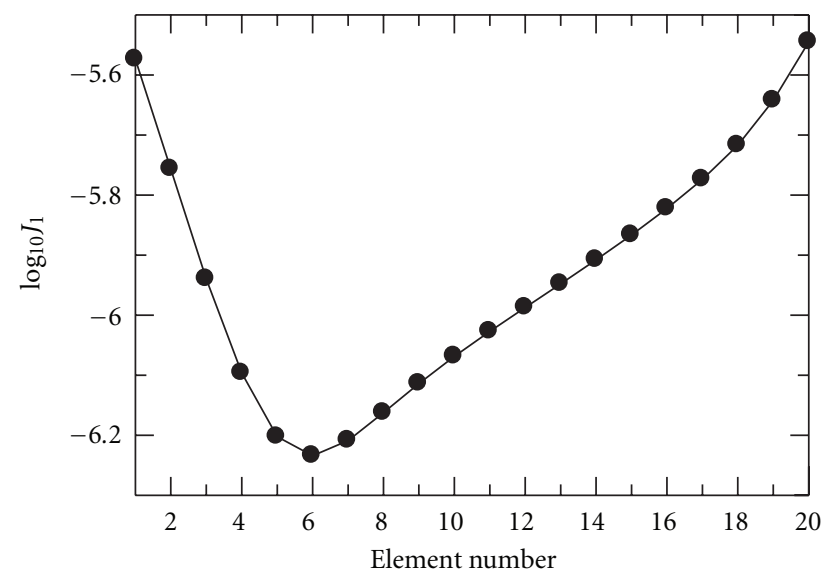

(a)

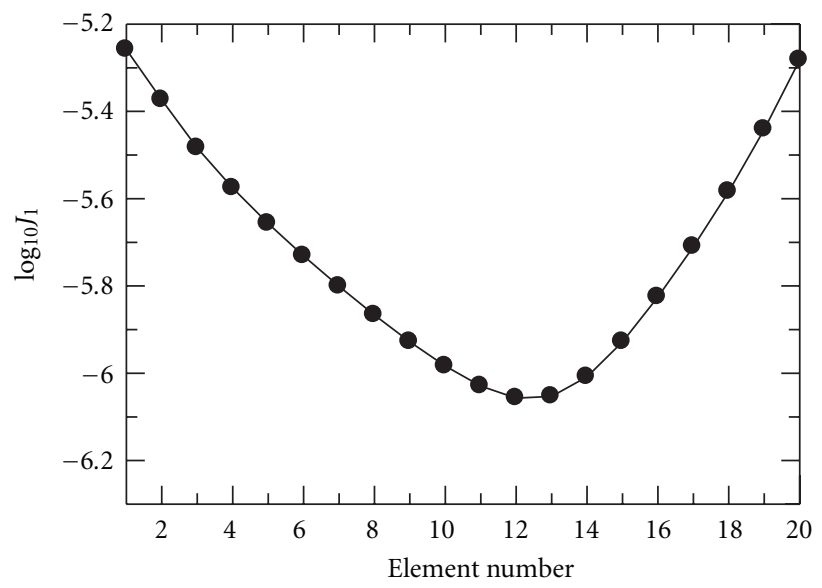

(c)

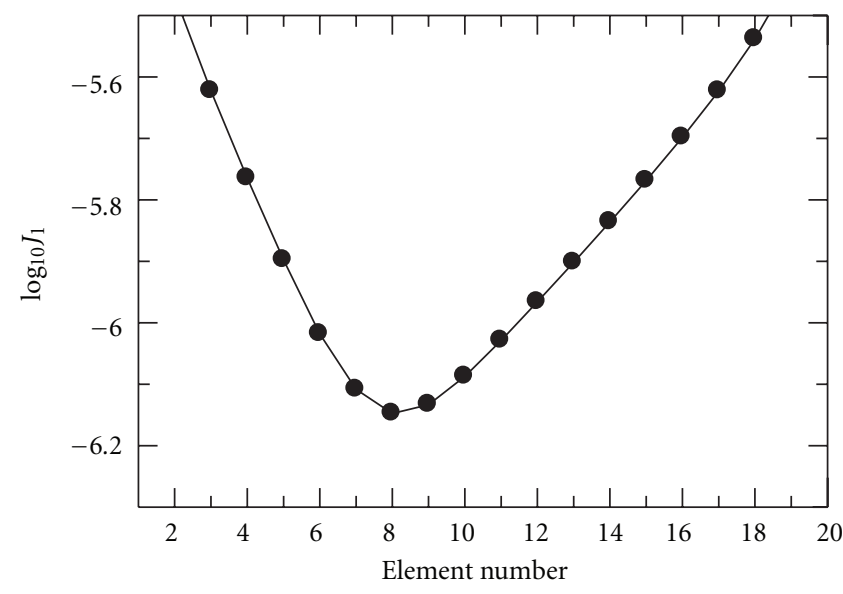

(b)

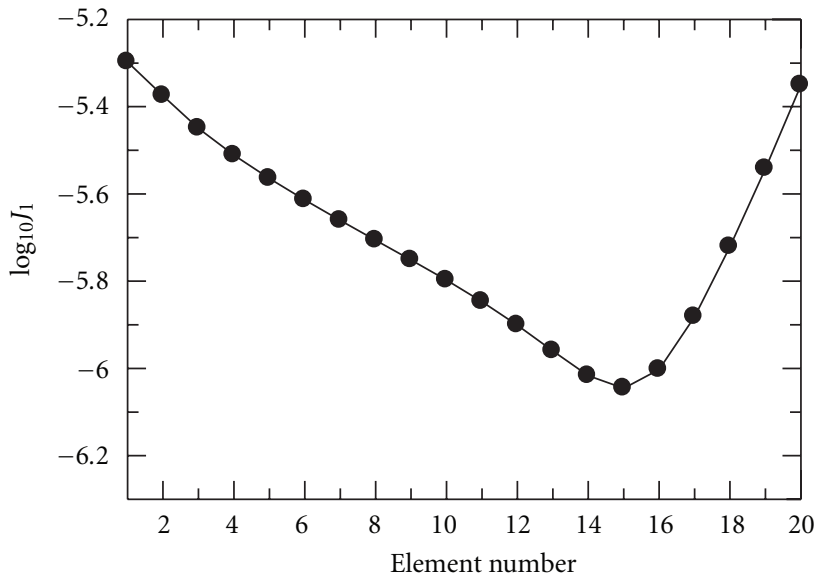

(d)

Figure 14: Objective function $J_{1}$ in the case of stationary rubbing. (a) In the case that the stationary rubbing occurs $150 \mathrm{~mm}$ from the left bearing. (b) In the case that the stationary rubbing occurs $200 \mathrm{~mm}$ from the left bearing. (c) In the case that the stationary rubbing occurs $300 \mathrm{~mm}$ from the left bearing. (d) In the case that the stationary rubbing occurs $350 \mathrm{~mm}$ from the left bearing.

TABLE 2: The severity of unbalance (Disk 1).

\begin{tabular}{|c|c|c|c|}
\hline & Exact value & Identified value & Error \\
\hline \multirow{2}{*}{$\begin{array}{c}\text { Case } 1 \text { unbalance }[\mathrm{g} \cdot \mathrm{mm} \text { ] } \\
\text { angle [deg.] }\end{array}$} & 12.0 & 13.7 & 1.7 \\
\hline & 0 & -15.9 & -15.9 \\
\hline \multirow{2}{*}{$\begin{array}{c}\text { Case } 2 \begin{array}{c}\text { unbalance }[\mathrm{g} \cdot \mathrm{mm} \text { ] } \\
\text { angle [deg.] }\end{array} \\
\end{array}$} & 12.0 & 14.1 & 2.1 \\
\hline & 45 & 33.1 & -12.0 \\
\hline \multirow{2}{*}{$\begin{array}{c}\text { Case } 3 \begin{array}{c}\text { unbalance }[\mathrm{g} \cdot \mathrm{mm} \text { ] } \\
\text { angle [deg.] }\end{array} \\
\end{array}$} & 12.0 & 14.0 & 2.0 \\
\hline & 90 & 77.0 & -13.0 \\
\hline \multirow{2}{*}{$\begin{array}{c}\text { Case } 4 \begin{array}{c}\text { unbalance }[\mathrm{g} \cdot \mathrm{mm} \text { ] } \\
\text { angle [deg.] }\end{array} \\
\end{array}$} & 12.0 & 12.9 & 0.9 \\
\hline & 135 & 120.9 & -14.1 \\
\hline \multirow{2}{*}{$\begin{array}{c}\text { Case } 5 \begin{array}{c}\text { unbalance }[\mathrm{g} \cdot \mathrm{mm} \text { ] } \\
\text { angle [deg.] }\end{array} \\
\end{array}$} & 12.0 & 11.5 & -0.5 \\
\hline & 180 & 164.9 & -15.1 \\
\hline \multirow{2}{*}{$\begin{array}{c}\text { Case } 6 \begin{array}{c}\text { unbalance }[\mathrm{g} \cdot \mathrm{mm}] \\
\text { angle [deg.] }\end{array} \\
\end{array}$} & 12.0 & 11.7 & -0.3 \\
\hline & 225 & 204.4 & -20.6 \\
\hline \multirow{2}{*}{$\begin{array}{c}\text { Case } 7 \begin{array}{c}\text { unbalance }[\mathrm{g} \cdot \mathrm{mm}] \\
\text { angle [deg.] }\end{array} \\
\end{array}$} & 12.0 & 12.5 & 0.5 \\
\hline & 270 & 244.0 & -26.0 \\
\hline \multirow{2}{*}{$\begin{array}{c}\text { Case } 8 \begin{array}{c}\text { unbalance }[\mathrm{g} \cdot \mathrm{mm} \text { ] } \\
\text { angle [deg.] }\end{array}\end{array}$} & 12.0 & 12.5 & 0.5 \\
\hline & 315 & 300.8 & -14.2 \\
\hline
\end{tabular}

TABLE 3: The severity of unbalance (Disk 2).

\begin{tabular}{|c|c|c|c|}
\hline & Exact value & Identified value & Error \\
\hline \multirow{2}{*}{ Case $1 \begin{array}{c}\text { unbalance }[\mathrm{g} \cdot \mathrm{mm} \text { ] } \\
\text { angle [deg.] }\end{array}$} & 12.0 & 13.1 & 1.1 \\
\hline & 0 & -2.1 & -2.1 \\
\hline \multirow{2}{*}{$\begin{array}{c}\text { Case } 2 \begin{array}{c}\text { unbalance }[\mathrm{g} \cdot \mathrm{mm}] \\
\text { angle [deg.] }\end{array} \\
\end{array}$} & 12.0 & 12.9 & 0.9 \\
\hline & 45 & 46.2 & 1.2 \\
\hline \multirow{2}{*}{$\begin{array}{c}\text { Case } 3 \begin{array}{c}\text { unbalance }[\mathrm{g} \cdot \mathrm{mm} \text { ] } \\
\text { angle [deg.] }\end{array}\end{array}$} & 12.0 & 13.8 & 1.8 \\
\hline & 90 & 77.0 & -13.0 \\
\hline \multirow{2}{*}{$\begin{array}{c}\text { Case } 4 \begin{array}{c}\text { unbalance }[\mathrm{g} \cdot \mathrm{mm}] \\
\text { angle [deg.] }\end{array} \\
\text {. }\end{array}$} & 12.0 & 12.8 & 0.8 \\
\hline & 135 & 116.5 & -18.5 \\
\hline \multirow{2}{*}{$\begin{array}{c}\text { Case } 5 \begin{array}{c}\text { unbalance }[\mathrm{g} \cdot \mathrm{mm} \text { ] } \\
\text { angle [deg. }\end{array} \\
\end{array}$} & 12.0 & 11.2 & -0.8 \\
\hline & 180 & 156.1 & -23.9 \\
\hline \multirow{2}{*}{ Case $6 \begin{array}{c}\text { unbalance }[\mathrm{g} \cdot \mathrm{mm}] \\
\text { angle [deg.] }\end{array}$} & 12.0 & 11.1 & -0.9 \\
\hline & 225 & 200.0 & -25.0 \\
\hline \multirow{2}{*}{ Case $7 \begin{array}{c}\text { unbalance }[\mathrm{g} \cdot \mathrm{mm} \text { ] } \\
\text { angle [deg.] }\end{array}$} & 12.0 & 11.4 & -0.6 \\
\hline & 270 & 252.8 & -17.2 \\
\hline \multirow{2}{*}{$\begin{array}{c}\text { Case } 8 \begin{array}{c}\text { unbalance }[\mathrm{g} \cdot \mathrm{mm}] \\
\text { angle [deg.] }\end{array}\end{array}$} & 12.0 & 11.8 & -0.2 \\
\hline & 315 & 300.8 & -14.2 \\
\hline
\end{tabular}




\section{Conclusion}

In this study, a stepwise primary diagnosis method for rotating machinery was proposed using a new procedure with respect to the vibration difference between the normal and the abnormal conditions. The applicability of the proposed method was checked against experimental data. In the case of a rotor system with unbalance, it was shown that the location of abnormality and its severity could be identified; in the case of a rotor system with stationary rubbing, the location of abnormality could be accurately identified. Therefore, it was confirmed that the proposed diagnosis method is feasible for actual application.

\section{Acknowledgment}

This work was supported in part by research Grant from JSPS Grant-in-Aid for Scientific Research (C) no. 21560238.

\section{References}

[1] Z. K. Peng, Z. Q. Lang, and S. A. Billings, "Crack detection using nonlinear output frequency response functions," Journal of Sound and Vibration, vol. 301, no. 3-5, pp. 777-788, 2007.

[2] G. Y. Xu, W. D. Zhu, and B. H. Emory, "Experimental and numerical investigation of structural damage detection using changes in natural frequencies," Journal of Vibration and Acoustics, vol. 129, no. 6, pp. 686-700, 2007.

[3] F. Wahl, G. Schmidt, and L. Forrai, "On the significance of antiresonance frequencies in experimental structural analysis," Journal of Sound and Vibration, vol. 219, no. 3, pp. 379-394, 1999.

[4] Y. Bamnios, E. Douka, and A. Trochidis, "Crack identification in beam structures using mechanical impedance," Journal of Sound and Vibration, vol. 256, no. 2, pp. 287-297, 2002.

[5] M. Dilena and A. Morassi, "The use of antiresonances for crack detection in beams," Journal of Sound and Vibration, vol. 276, no. 1-2, pp. 195-214, 2004.

[6] A. S. Sekhar, "Crack identification in a rotor system: a modelbased approach," Journal of Sound and Vibration, vol. 270, no. 4-5, pp. 887-902, 2004.

[7] A. S. Sekhar, "Model-based identification of two cracks in a rotor system," Mechanical Systems and Signal Processing, vol. 18, no. 4, pp. 977-983, 2004.

[8] N. Bachschmid, P. Pennacchi, and A. Vania, "Identification of multiple faults in rotor systems," Journal of Sound and Vibration, vol. 254, no. 2, pp. 327-366, 2003.

[9] P. Pennacchi, N. Bachschmid, A. Vania, G. A. Zanetta, and L. Gregori, "Use of modal representation for the supporting structure in model-based fault identification of large rotating machinery-part 1: theoretical remarks," Mechanical Systems and Signal Processing, vol. 20, no. 3, pp. 662-681, 2006.

[10] P. Pennacchi, A. Vania, and N. Bachschmid, "Increasing the robustness of fault identification in rotor dynamics by means of M-estimators," Mechanical Systems and Signal Processing, vol. 21, no. 8, pp. 3003-3029, 2007.

[11] S. Kawamura, H. Tao, H. Minamoto, and H. M. Zahid, "Development of a stepwise primary diagnosis method of a beam using a force identification and optimization approach," Journal of Sound and Vibration, vol. 311, no. 3-5, pp. 861-873, 2008.

[12] S. Kawamura, J. Yamamoto, and H. Minamoto, "Model-based diagnosis approach for a beam structure using the modified mathematical model," Journal of System Design and Dynamics, vol. 5, no. 2, pp. 306-319, 2011.

[13] S. Kawamura, J. Yamamoto, and H. Minamoto, "A regularization method for a stepwise primary diagnosis method of a beam structure using a force identification technique," Journal of System Design and Dynamics, vol. 5, no. 4, pp. 612-623, 2011. 

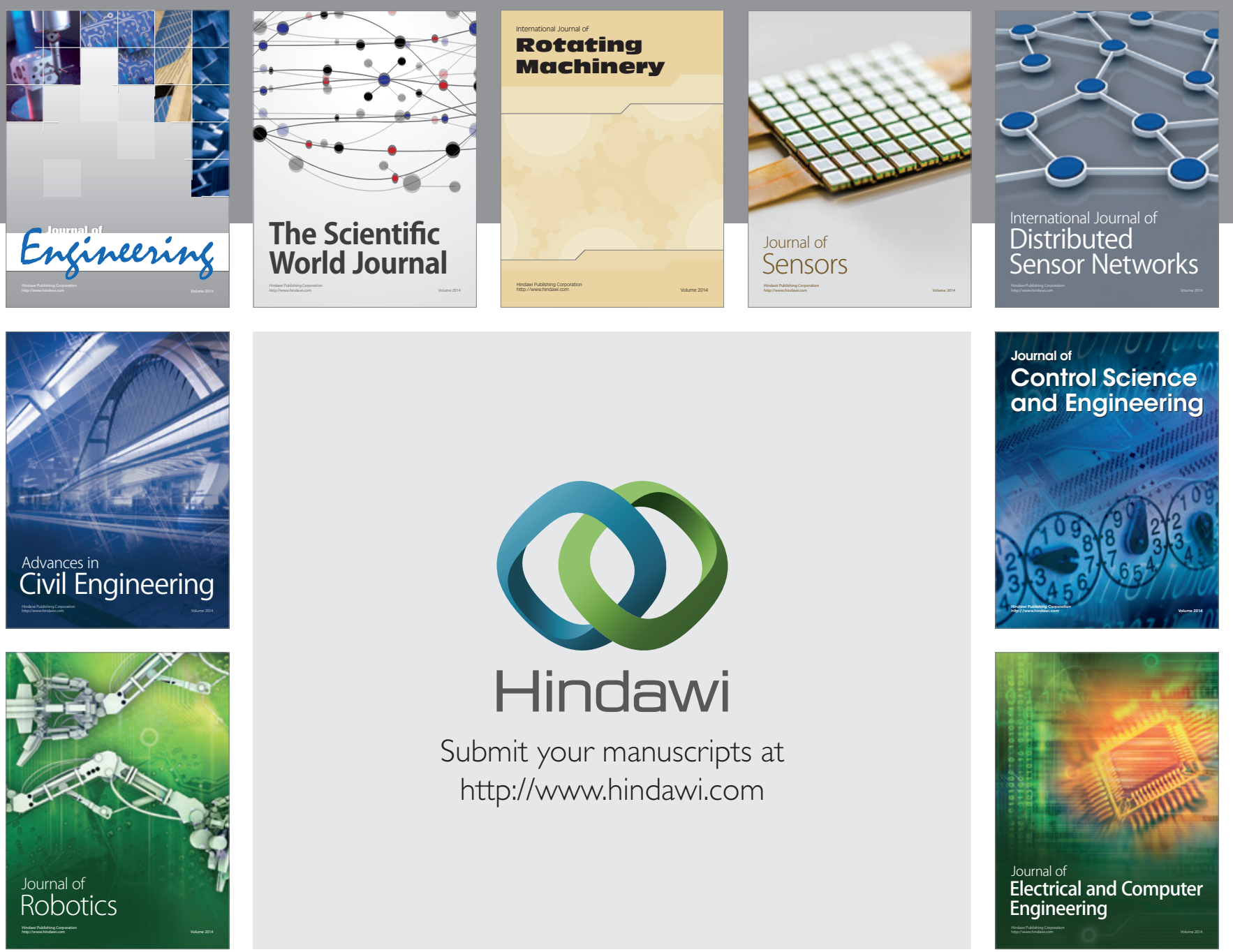

Submit your manuscripts at

http://www.hindawi.com
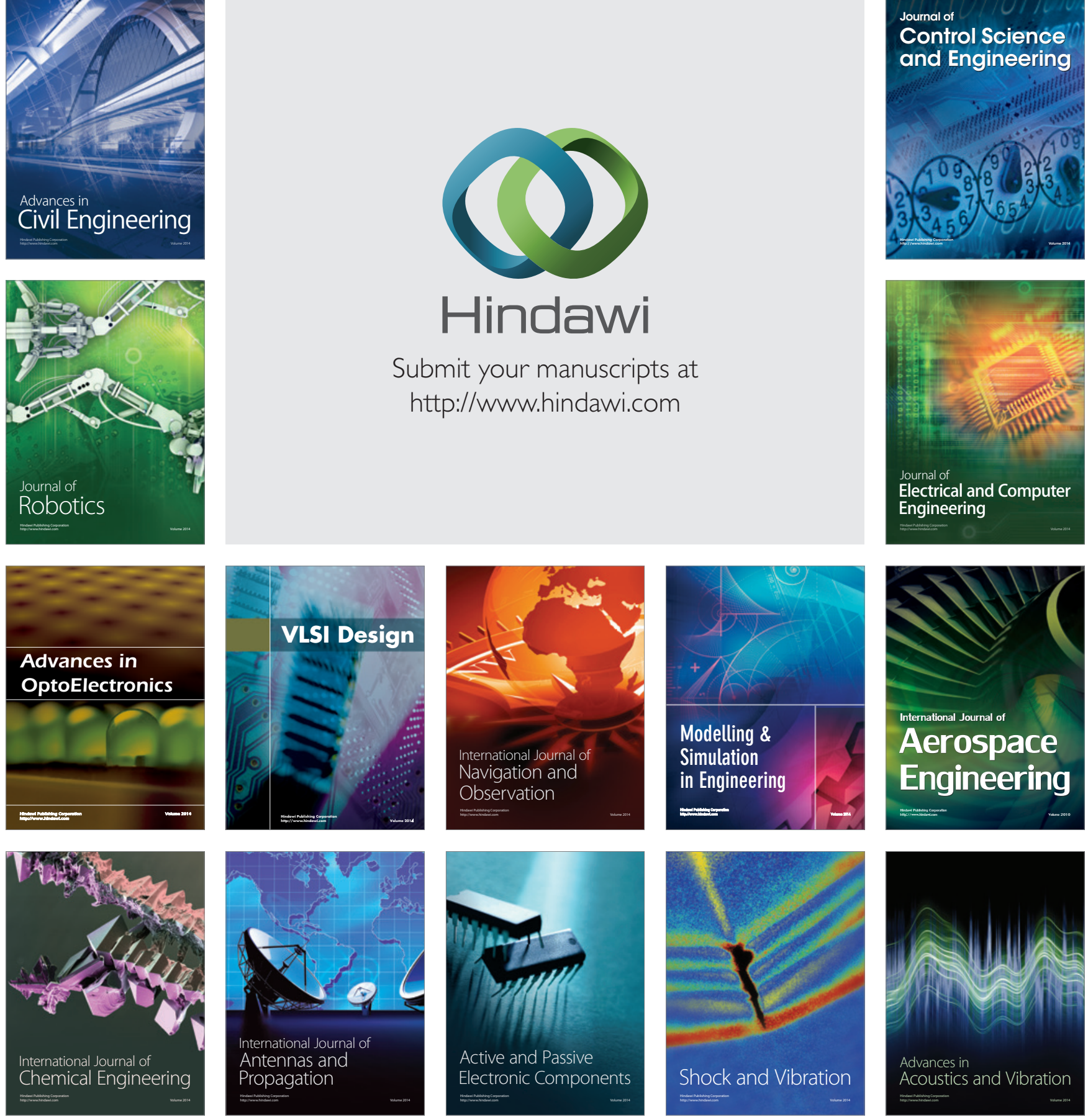